\title{
THE EFFECTS OF HEAT TREATMENT AND MICROSTRUCTURE VARIATIONS ON DISK SUPERALLOY PROPERTIES AT HIGH TEMPERATURE
}

\author{
Timothy P. Gabb ${ }^{1}$, John Gayda ${ }^{1}$, Jack Telesman ${ }^{1}$, Anita Garg ${ }^{3}$ \\ ${ }^{1}$ NASA Glenn Research Center; 21000 Brookpark Rd.; Cleveland, OH 44135 \\ ${ }^{3}$ University of Toledo; 21000 Brookpark Rd.; Cleveland, OH 44135
}

Keywords: disk, superalloys, microstructure

\begin{abstract}
The effects of heat treatment and resulting microstructure variations on high temperature mechanical properties were assessed for a powder metallurgy disk superalloy LSHR. Blanks were consistently supersolvus solution heat treated and quenched at two cooling rates, than aged at varying temperatures and times. Tensile, creep, and dwell fatigue crack growth tests were then performed at $704^{\circ} \mathrm{C}$. $\gamma^{\prime}$ precipitate microstructures were quantified. Relationships between heat treatment-microstructure, heat treatment-mechanical properties, and microstructuremechanical properties were assessed.
\end{abstract}

\section{Introduction}

Advanced powder metallurgy disk alloys such as ME3 (also known as Rene 104 and ME16) [1], Alloy 10 [2, 3], and LSHR [4] have been designed to allow higher rim temperature capabilities of $650-704^{\circ} \mathrm{C}$ for selected applications. Such capabilities would not only allow higher compressor exit temperatures, but also allow the full utilization of advanced combustor and airfoil concepts under development. It is well known that the tensile and creep properties of disk superalloys at elevated temperatures vary significantly with heat treatment, even for a constant grain size [5]. More recent work has shown that dwell fatigue crack growth resistance at high temperatures can also be highly sensitive to heat treatment [6]. Compromises need to be made among the mechanical properties, as these three properties cannot be simultaneously maximized with the same heat treatment and microstructure. For example, faster cooling rates have been shown to improve tensile and creep resistance, but can harm ductility and dwell fatigue crack growth resistance [6].

The changes in various mechanical properties due to heat treatment in similar disk superalloys have been recently related to effects on microstructural features including morphology of the $\gamma^{\prime}$ precipitates [7], grain boundary serrations [8], and grain boundary carbides [9]. Processing-microstructure models are in active development $[10,11]$ that could potentially model how processing paths can tailor such microstructural features. Microstructuremechanical property models are now being adapted to newer disk superalloys for high temperature applications [12]. Thus, a good understanding of the relationships between heat treatments, microstructures, and the relevant mechanical properties is necessary to allow design of processing paths that achieve microstructures with preferred combinations of properties at high rim temperatures.

It is desirable to relate mechanical properties to microstructural parameters in physics-based models. However, to be useful, it is desirable that these models have resolution at least as good as that from more widely used process-property models [5].

A study was therefore conducted to examine the effects of different quench and aging heat treatments on microstructures and high temperature mechanical properties of the disk superalloy LSHR. Powder metallurgy-processed material blanks were first supersolvus solution heat treated for a consistent grain size. They were then subjected to either slow cooling (SC) or fast cooling (FC) quenches, and aged at various temperatures of 775 to $855^{\circ} \mathrm{C}$, and times of 0 to $8 \mathrm{~h}$. Single step and two-step aging heat treatments were employed. Microstructural features were evaluated. Tensile, creep, and dwell fatigue crack growth tests were then performed at $704^{\circ} \mathrm{C}$, and the compromises among properties were compared and related to the microstructures observed.

\section{Materials and Procedure}

LSHR superalloy powder having a composition in weight percent of $3.5 \mathrm{Al}, 0.03 \mathrm{~B}, 0.03 \mathrm{C}, 20.7 \mathrm{Co}, 12.5 \mathrm{Cr}, 2.7 \mathrm{Mo}, 1.5 \mathrm{Nb}, 1.6 \mathrm{Ta}$, $3.5 \mathrm{Ti}, 4.3 \mathrm{~W}, 0.05 \mathrm{Zr}$, bal. $\mathrm{Ni}$ and trace impurities was obtained from Special Metals Corp. The powder was atomized in argon, canned, hot isostatically pressed, extruded and isothermally forged into a flat disk. Rectangular blanks about $1.5 \mathrm{~cm}$ square and $5 \mathrm{~cm}$ long or $1.3 \mathrm{~cm}$ and $9 \mathrm{~cm}$ long were then extracted from the forged pancake. The blanks were placed vertically in either an open or closed steel fixture and then supersolvus solution heat treated at $1171^{\circ} \mathrm{C}$ in a resistance heating furnace. The fixture was then removed to cool in static air. Average cooling rates for the cores of $5 \mathrm{~cm}$ long blanks in the closed and open fixtures were 72 and $202^{\circ} \mathrm{C}$ per minute, respectively. Average cooling rates for the cores of $9 \mathrm{~cm}$ long blanks in the closed and open fixtures were higher, 79 and $249^{\circ} \mathrm{C}$ per minute. Blanks were then aged at $775-$ $855^{\circ} \mathrm{C}$ for times of 1 to $8 \mathrm{~h}$, as listed in Table I. Unaged blanks were also prepared. The $5 \mathrm{~cm}$ long blanks were then machined into tensile and fatigue crack growth specimens, while $9 \mathrm{~cm}$ blanks were machined into creep specimens.

Tensile tests were performed at $704^{\circ} \mathrm{C}$ on specimens having a gage diameter of $0.41 \mathrm{~cm}$ and gage length of $2.5 \mathrm{~cm}$, in universal testing machines using resistance heating and axial extensometers, according to ASTM E21. Creep tests were performed at $704^{\circ} \mathrm{C}$ with a stress of $690 \mathrm{MPa}$ on specimens having a gage diameter of $0.64 \mathrm{~cm}$ and gage length of $3.8 \mathrm{~cm}$ in uniaxial lever arm constant load creep frames using resistance heating furnaces and shouldermounted extensometers, according to ASTM E139. Fatigue crack growth tests were performed at $704^{\circ} \mathrm{C}$ with a maximum stress of $620 \mathrm{MPa}$ on specimens having a rectangular gage section $1 \mathrm{~cm}$ 
wide and $0.46 \mathrm{~cm}$ thick with a surface flaw about $0.036 \mathrm{~cm}$ wide and $0.018 \mathrm{~cm}$ deep produced by electro-discharge machining. These tests were performed in a closed-loop servohydraulic test machine using resistance heating and potential drop measurement of crack growth. Pre-cracking was first performed at room temperature. Cyclic dwell tests were performed at $704^{\circ} \mathrm{C}$ with a $90 \mathrm{~s}$ dwell at maximum stress, using a stress ratio of 0.05 .

Table I. Heat Treatment Conditions

\begin{tabular}{|c|c|c|}
\hline Cooling Rate & Aging Temperature-C & Aging Time-h \\
\hline SC & 0 & 0 \\
\hline FC & 0 & 0 \\
\hline SC & 775 & 1 \\
\hline SC & 775 & 8 \\
\hline FC & 775 & 8 \\
\hline SC & 815 & 8 \\
\hline FC & 815 & 1 \\
\hline FC & 815 & 3 \\
\hline FC & 815 & 8 \\
\hline SC & 855 & 1 \\
\hline SC & 855 & 8 \\
\hline FC & 855 & 1 \\
\hline FC & 855 & 8 \\
\hline SC & $855 / 775$ & $1 / 8$ \\
\hline FC & $855 / 775$ & $1 / 8$ \\
\hline SC & $855 / 775$ & $4 / 8$ \\
\hline FC & $855 / 775$ & $8 / 8$ \\
\hline SC & $855 / 775$ & $8 / 8$ \\
\hline FC & $855 / 775$ & \\
\hline & &
\end{tabular}

Grain sizes were determined from etched metallographic sections according to ASTM E112 linear intercept procedures, using circular grid overlays on optical images. Precipitate microstructures were primarily characterized on thinned foils using transmission electron microscopy (TEM). Precipitates were imaged using dark field conditions from superlattice reflections using only grains with a $<001>$ zone axis oriented near the foil normal. SigmaScan ${ }^{\circledR}$ image analysis software was used to measure the area of individual precipitates. Diameter and radius of each were then consistently calculated based on the equivalent circular area. Precipitates having a diameter above $100 \mathrm{~nm}$ were classified as secondary $\gamma^{\prime}$ precipitates $\left(\gamma_{\mathrm{s}}{ }^{\prime}\right)$, those below $100 \mathrm{~nm}$ diameter were considered tertiary $\gamma^{\prime}$ precipitates $\left(\gamma_{\mathbf{T}}{ }^{\prime}\right)$. Area fractions of $\gamma_{S}^{\prime}$ and $\gamma_{T}^{\prime}$ were determined using point counting techniques. Field emission scanning electron microscopy was performed on metallographic sections for comparison purposes.

In order to clearly assess and compare the effects of processing and microstructural variables on the responses, multiple linear regression was performed on each of the responses, using forward and reverse stepwise selection of the applicable variables. Each variable $(\mathrm{V})$ was first standardized $(\mathbf{V})$ using the variable range $\left(\mathrm{V}_{\text {range }}\right)$ and variable mid-value $\left(\mathrm{V}_{\mathrm{mid}}\right)$ in Equation 1, such that all would consistently vary between -1 and +1 .

$$
\mathbf{V}=\left(\mathrm{V}-\mathrm{V}_{\text {mid }}\right) /\left(\mathrm{V}_{\text {range }} / 2\right)
$$

A $90 \%$ probability of significance was required for inclusion of any variable during stepwise selection of significant variables. The correlation coefficient, adjusted for the number of included variables $\left(\mathrm{R}_{\text {adj }}^{2}\right.$ ), was used as a measure of the applicability of the regression, with $\mathrm{R}_{\text {adj. }}^{2} \geq 0.25$ indicating $\geq 50 \%$ of the response variation is accounted for by the regression equation. The estimated standard deviation of the residual error (Rms Error) was used to assess the remaining error in response after regression.

\section{Results and Discussion}

Heat Treatment-Microstructure Relationships

All of the different heat treatments produced grain sizes between 27 and $36 \mu \mathrm{m}$, Fig. 1. Serrated grain boundaries were usually observed for the slower cooled material, while more straight grain boundaries were observed for the faster cooled material. $\mathrm{M}_{23} \mathrm{C}_{6}$ carbides along grain boundaries were of similar volume fraction for all aged specimens examined.

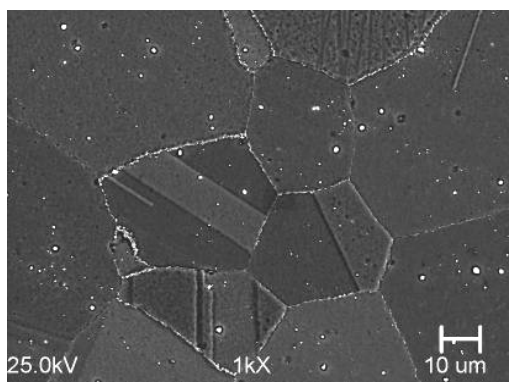

a. $\mathrm{FC}+775^{\circ} \mathrm{C} / 8 \mathrm{~h}$
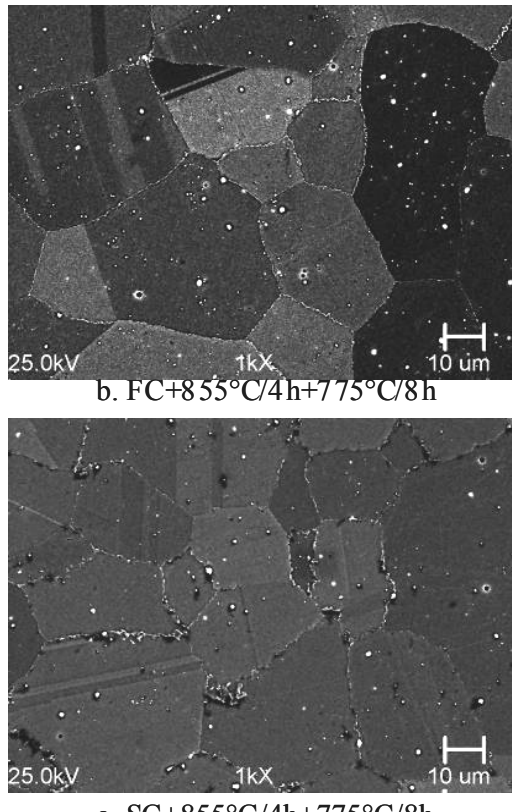

c. $\mathrm{SC}+855^{\circ} \mathrm{C} / 4 \mathrm{~h}+775^{\circ} \mathrm{C} / 8 \mathrm{~h}$

Fig. 1. Typical grain microstructures.

Microstructures are compared for single step aging heat treatments at time endpoints in Fig. 2. Microstructures are compared for two-step aging heat treatments in Fig. 3. $\gamma_{\mathbf{S}}{ }^{\prime}$ and $\gamma_{\mathbf{T}}{ }^{\prime}$ sizes and area fractions were quantified for most heat treatments. Typical $\gamma_{\mathbf{S}}{ }^{\prime}$ and $\gamma_{\mathbf{T}}{ }^{\prime}$ size-frequency distributions are shown in Fig. 4. 


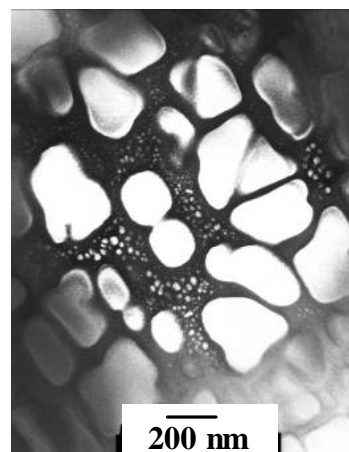

a. SC

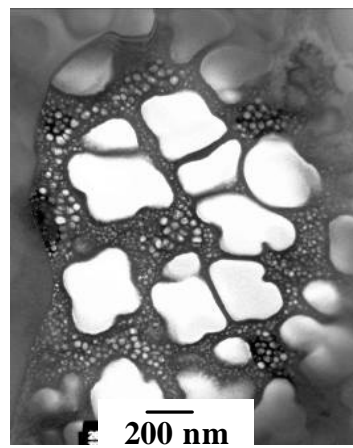

$\mathrm{SC}+775^{\circ} \mathrm{C} / 8 \mathrm{~h}$

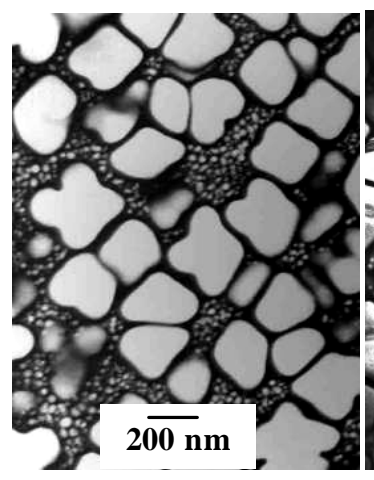

e. $\mathrm{SC}+815^{\circ} \mathrm{C} / 8 \mathrm{~h}$

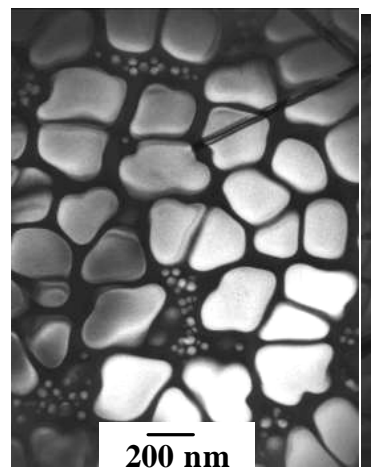

g. $\mathrm{SC}+855^{\circ} \mathrm{C} / 8 \mathrm{~h}$

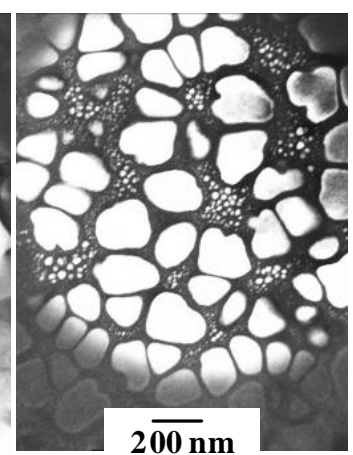

b. FC

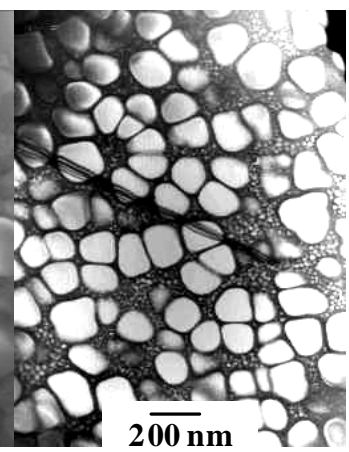

d. $\mathrm{FC}+775^{\circ} \mathrm{C} / 8 \mathrm{~h}$

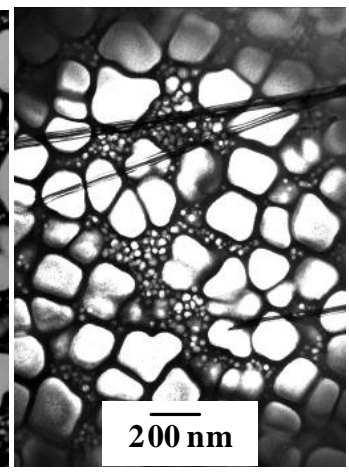

f. $\mathrm{FC}+815^{\circ} \mathrm{C} / 8 \mathrm{~h}$

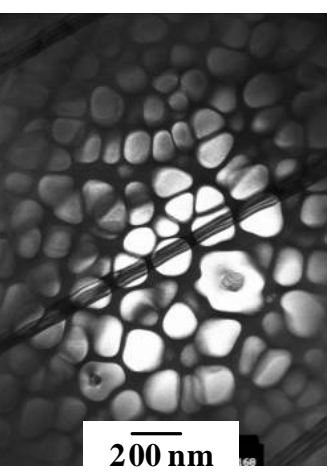

h. $\mathrm{FC}+855^{\circ} \mathrm{C} / 8 \mathrm{~h}$
Fig. 2. Typical $\gamma^{\prime}$ for quenched and one-step aged cases.
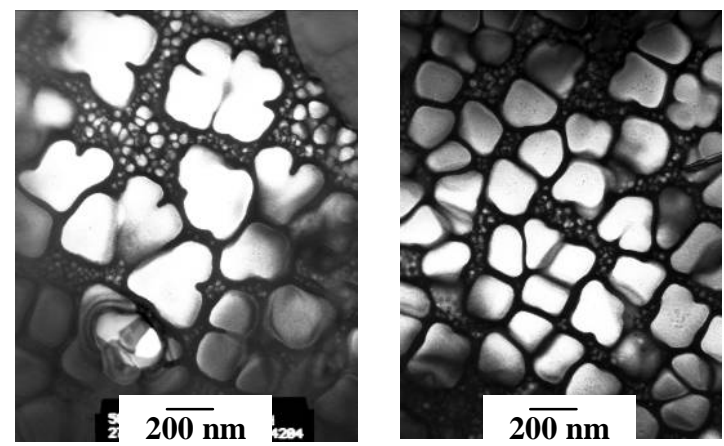

a. $\mathrm{SC}+855^{\circ} \mathrm{C} / 1 \mathrm{~h}+775^{\circ} \mathrm{C} / 8 \mathrm{~h}$

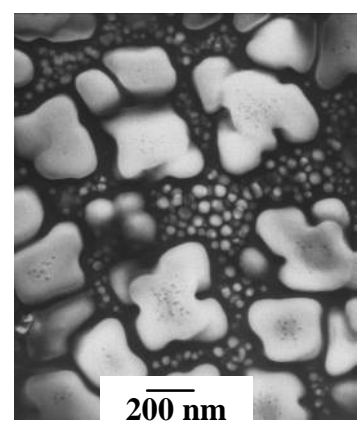

c. $\mathrm{SC}+855^{\circ} \mathrm{C} / 4 \mathrm{~h}+775^{\circ} \mathrm{C} / 8 \mathrm{~h}$

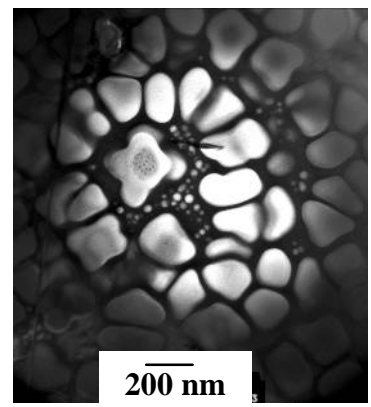

b. $\mathrm{FC}+855^{\circ} \mathrm{C} / 1 \mathrm{~h}+775^{\circ} \mathrm{C} / 8 \mathrm{~h}$

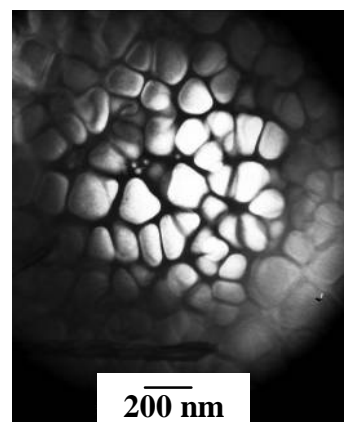

d. $\mathrm{FC}+855^{\circ} \mathrm{C} / 4 \mathrm{~h}+775^{\circ} \mathrm{C} / 8 \mathrm{~h}$

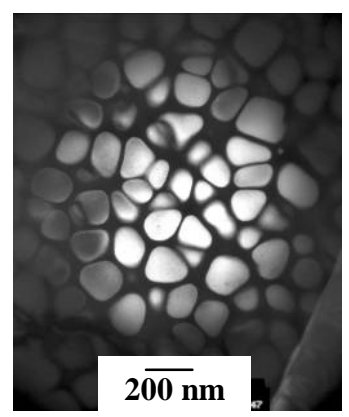

e. $\mathrm{SC}+855^{\circ} \mathrm{C} / 8 \mathrm{~h}+775^{\circ} \mathrm{C} / 8 \mathrm{~h} \quad$ f. $\mathrm{FC}+855^{\circ} \mathrm{C} / 8 \mathrm{~h}+775^{\circ} \mathrm{C} / 8 \mathrm{~h}$

Fig. 3. Typical $\gamma^{\prime}$ for two-step aged cases.

$\gamma_{\mathrm{s}}^{\prime}$ sizes were not all normally distributed, as shown in Fig. 4. Slow cooled specimens had what appeared to be bimodal secondary $\gamma^{\prime}$ size distributions. Examination of numerous thin foils indicated this was primarily due to the dendritic growth at the cuboidal corners of $\gamma_{\mathbf{s}}{ }^{\prime}$. Grains with normals oriented near an $\{001\}$ crystallographic plane were usually analyzed for consistency. Random metallographic sectioning near this plane of such precipitates would alternatively clip the separated corner lobes or cut through the joined core, largely accounting for the bimodal size distributions observed here. $\gamma_{\mathrm{S}}{ }^{\prime}$ and $\gamma_{\mathrm{T}}{ }^{\prime}$ median radii were therefore compared for all cases.

Regressions were performed to model $\gamma_{\mathbf{S}}{ }^{\prime}$ and $\gamma_{\mathbf{T}}{ }^{\prime}$ size and volume fractions using the standardized variables of cooling rate $(\mathbf{R})$, aging temperature $(\mathbf{T})$, and cube root of aging time $\left(\mathbf{t}^{\mathbf{1} / 3}\right)$. The resulting equations are summarized in Table II. Data from specimens given two-step ages were not included in these regressions, in order to directly determine the effects of individual aging temperature and time combinations. Data from asquenched specimens without aging heat treatments were not 
directly included in these regressions. However, the growth in $\gamma_{\mathbf{T}}{ }^{\prime}$ radius was obtained from the initial $\gamma_{T}{ }^{\prime}$ size of specimens asquenched at the appropriate cooling rate, and used in the regressions.

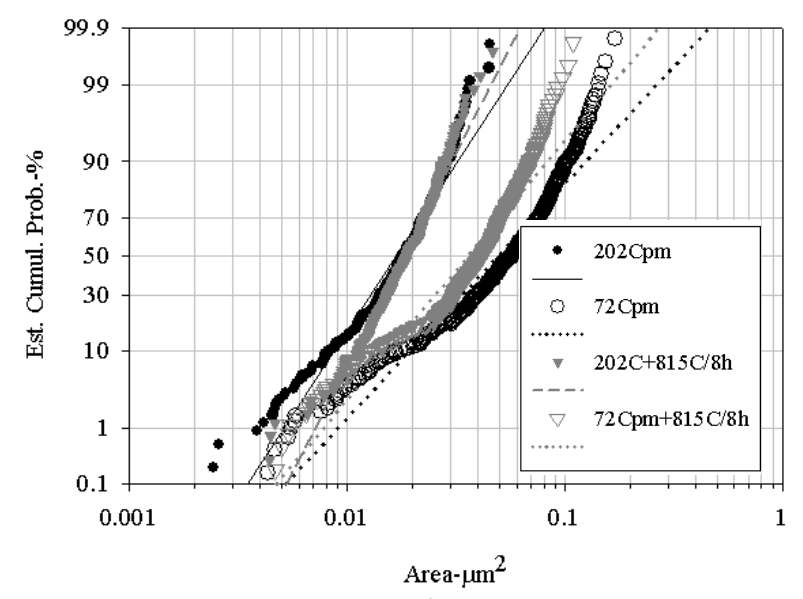

a. Secondary $\gamma^{\prime}$ size distributions.

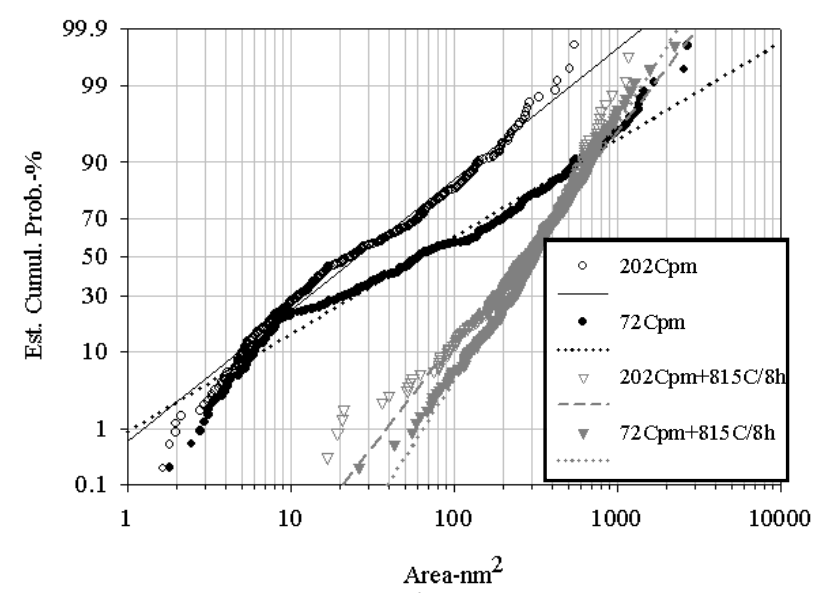

b. Tertiary $\gamma^{\prime}$ size distributions.

Fig. 4. $\gamma^{\prime}$ size-frequency distributions.

Table II. Heat Treatment-Microstructure Regression Results

\begin{tabular}{|c|c|c|c|}
\hline Response & Equation & $\mathrm{R}_{\mathrm{adj}}{ }^{2}$ & $\begin{array}{l}\text { Rms } \\
\text { Error }\end{array}$ \\
\hline $\begin{array}{c}\gamma_{\mathrm{s}}^{\prime} \text { Radius- } \\
\mathrm{nm}\end{array}$ & $88.6-31.5 \mathbf{R}$ & 0.855 & 10.0 \\
\hline $\begin{array}{c}\gamma_{\mathrm{T}}^{\prime} \text { Radius } \\
\text { Increase- } \\
\mathrm{nm}\end{array}$ & 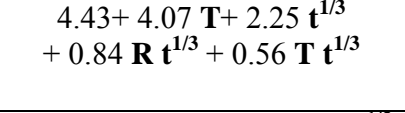 & 0.979 & 0.5 \\
\hline $\begin{array}{l}\gamma_{s}^{\prime} \text { Vol. } \\
\text { Fraction }\end{array}$ & $0.562+0.009 \mathbf{R}+0.021 \mathbf{T ~ t}^{1 / 3}$ & 0.818 & 0.009 \\
\hline $\begin{array}{l}\gamma_{\mathrm{T}}^{\prime} \text { Vol. } \\
\text { Fraction }\end{array}$ & $0.018-0.009 \mathbf{R}-0.021 \mathbf{T ~ t}^{1 / 3}$ & 0.810 & 0.009 \\
\hline
\end{tabular}

Inspection of the micrographs and scatter plots shown in Fig. 5 indicated $\gamma_{s}^{\prime}$ size increased with decreasing solution heat treatment cooling rate, as expected. Slow cooling rates also encourage the dendritic growth at cube corners. $\gamma_{s}^{\prime}$ size did not significantly vary with aging time or temperature. Regression analysis confirmed that $\gamma_{\mathrm{s}}{ }^{\prime}$ radius significantly increased only with decreasing cooling rate. A wide size range of $\gamma_{T}{ }^{\prime}$ was present in the as-quenched samples, extending to very fine $\gamma_{\mathbf{T}}{ }^{\prime}$. This gave a lower median and mean size than for all samples given aging heat treatments. The wide range produced reduced slopes in the cumulative probability curves of Fig. 4. $\quad \gamma_{\mathbf{T}}{ }^{\prime}$ size increased and size range decreased with the aging heat treatments. Regressions confirmed $\gamma_{\mathbf{T}}{ }^{\prime}$ radius increase was proportional to temperature and cube root of aging time, consistent with Lifshitz-Slyozov-Wagner (LSW) coarsening theory, although allowance for effects of disk superalloy $\gamma^{\prime}$ volume fraction were not included [13]. Regression also indicated enhanced $\gamma_{T}^{\prime}$ coarsening for combinations of high cooling rate with long aging time. As-quenched $\gamma_{\mathrm{s}}^{\prime}$ volume fraction appeared to increase and $\gamma_{\mathbf{T}}^{\prime}$ volume fraction decreased with increasing cooling rate. Aging heat treatments at $855^{\circ} \mathrm{C}$ appeared to further decrease $\gamma_{\mathbf{T}}{ }^{\prime}$ volume fraction. Regressions confirmed $\gamma_{s}^{\prime}$ volume fraction significantly increased with increasing cooling rate, and was enhanced for combinations of high aging temperature and long aging time. Conversely, $\gamma_{\mathbf{T}}{ }^{\prime}$ volume fraction significantly increased with decreasing cooling rate and was enhanced for combinations of low cooling rate and short aging time. The second step of $775^{\circ} \mathrm{C} / 8 \mathrm{~h}$ in two-step aging heat treatments appeared to provide only a minor addition of small $\gamma_{\mathrm{T}}{ }^{\prime}$ to the large $\gamma_{\mathrm{T}}{ }^{\prime}$ produced by the first step at $855^{\circ} \mathrm{C}$.

These trends provided insights into the interrelationships among the various processing parameters and the $\gamma_{\mathrm{S}}{ }^{\prime}$ and $\gamma_{\mathrm{T}}{ }^{\prime}$ sizes and area fractions. The relative stability of $\gamma_{s^{\prime}}$ size during aging has been reported for disk superalloys of lower $\gamma^{\prime}$ content $[14,15]$. No splitting of $\gamma_{s^{\prime}}$ [16] was evident for the short aging times examined here. LSW coarsening of $\gamma_{T}^{\prime}$ in disk superalloys during aging was also reported in several studies $[15,16,17]$. However, the effects of cooling rate on $\gamma_{\mathbf{T}}{ }^{\prime}$ coarsening response and relative $\gamma_{S}^{\prime}$ versus $\gamma_{T}{ }^{\prime}$ phase volume fractions were unexpected. Increased $\gamma_{s^{\prime}}$ and reduced $\gamma_{T}^{\prime}$ volume fractions with increasing cooling rate have been observed in ME3 [18]. But the rapid reduction of $\gamma_{\mathrm{T}}{ }^{\prime}$ volume fraction and increase of $\gamma_{s}^{\prime}$ content for high cooling rate samples given high temperature aging heat treatments was surprising, for the short aging times involved. It has been reported that extended aging of a disk superalloy NR3 at $800^{\circ} \mathrm{C}$ for $1000 \mathrm{~h}$ completely eliminated $\gamma_{\mathbf{T}}^{\prime}$ [17]. This was nearly accomplished at $855^{\circ} \mathrm{C}$ in only $8 \mathrm{~h}$ for LSHR given a fast cool quench. For the fine $\gamma_{s}^{\prime}$ produced by fast cooling rates, the interparticle distances are apparently short enough to allow $\gamma_{\mathrm{T}}{ }^{\prime}$ solute to be captured by $\gamma_{\mathrm{s}}^{\prime}$ during coarsening. While not substantially increasing median $\gamma_{s^{\prime}}^{\prime}$ size, this did allow some local joining between nearby $\gamma_{s^{\prime}}^{\prime}$ precipitates (Fig. 2, 3) and increased $\gamma_{\mathrm{s}}{ }^{\prime}$ volume fraction, while decreasing $\gamma_{\mathbf{T}}{ }^{\prime}$ volume fraction.

Heat Treatment-Mechanical Property Relationships

The corresponding mechanical properties for all the different heat treatments are compared in Fig. 6. Yield strength, ultimate strength, ductility, $0.2 \%$ creep life, and dwell fatigue crack growth rates are shown for tests at $704^{\circ} \mathrm{C}$. Linear regressions were performed to model these properties using the standardized variables cooling rate $(\mathbf{R})$, aging temperature $(\mathbf{T})$, and aging time (t). Data from as-quenched specimens were not included in these regressions, due to their divergent microstructures and mechanical responses. The resulting regression equations are summarized in Table III, and regression lines are included in Fig. 6. 


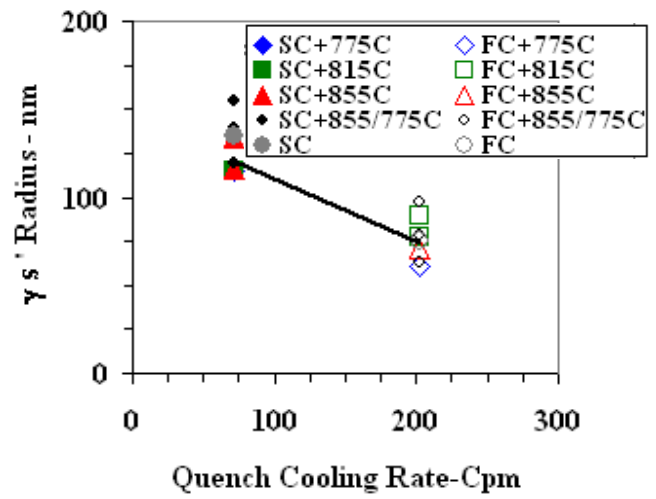

a. Secondary $\gamma^{\prime}$ radius.

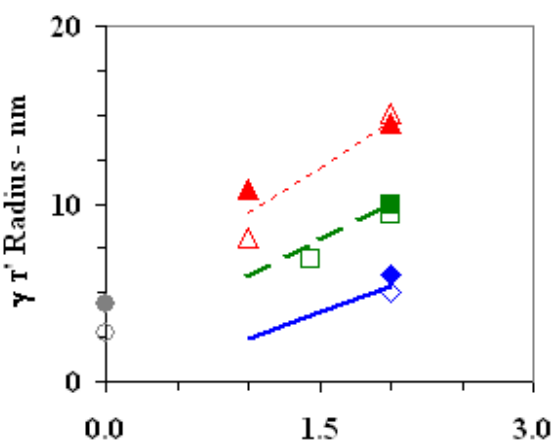

(Aging Time-h) ${ }^{1 / 3}$

b. Tertiary $\gamma^{\prime}$ radius.

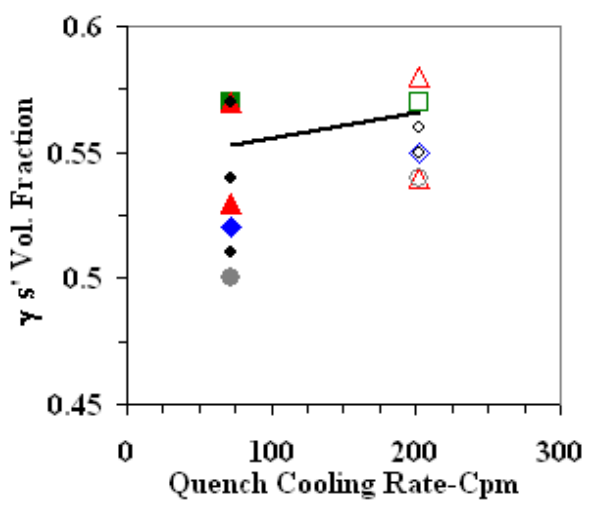

c. Secondary $\gamma^{\prime}$ vol. fraction.

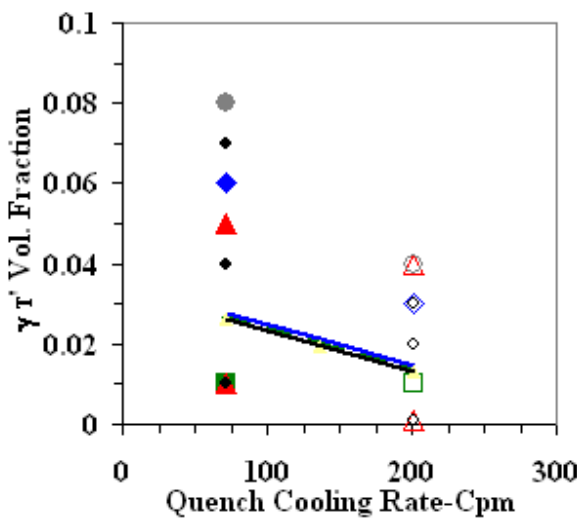

d. Tertiary $\gamma^{\prime}$ vol. fraction.

Fig. 5. Heat treatment-microstructure relationships.

Yield strength and tensile strength increased with increasing cooling rate, as has been reported earlier for many disk superalloys $[5,6]$. Tensile strength was increased by all the aging heat treatments from the as-quenched values, while yield strength increased more for FC specimens. Among the cases of different aging heat treatments, ultimate strength was comparable at all aging temperature/time combinations for the FC blanks, but decreased with increasing aging temperatures for the SC blanks. Regressions indicated that yield strength increased strongly with increasing cooling rate, and increased moderately for combinations of low aging temperature and high aging time. Ultimate strength increased strongly with increasing cooling rate, and increased moderately with decreasing aging temperature. Tensile ductility significantly increased with decreasing cooling rate, and was enhanced for combinations of low cooling rate, high aging temperature, and high aging time. Regressions indicated creep life increased strongly with increasing cooling rate, and increased moderately with decreasing aging temperature and aging time. Dwell fatigue crack growth rates decreased with decreasing cooling rate, increasing aging temperature and increasing aging time.

These relationships allowed consideration of mechanical property combinations for different heat treatment conditions. Tensile yield and ultimate strengths responded in similar manners to the heat treat parameters. However, yield strength varied more with different aging temperatures and times than for ultimate strength. Meanwhile ductility increased with decreasing cooling rates and increasing aging temperature and time. The time-dependent mechanical properties, creep and dwell fatigue crack growth resistances, responded in opposite directions to these heat treatments. Increasing cooling rate and decreasing aging temperature generally improved creep resistance, but harmed dwell fatigue crack growth resistance. The effects of heat treatments and microstructure on dwell fatigue crack growth rate are examined in detail elsewhere in these proceedings [19]. However, it appeared possible to get favorable combinations of both tensile and time-dependent properties using high cooling rates with high aging temperatures and times, or low cooling rates with low aging temperature and long aging times.

Table III. Heat Treatment-Mechanical Property Regressions.

\begin{tabular}{|c|c|c|c|}
\hline Response & Equation & $\mathrm{R}_{\mathbf{a d j}}{ }^{2}$ & $\begin{array}{c}\text { Rms } \\
\text { Error }\end{array}$ \\
\hline $\begin{array}{c}\text { Yield } \\
\text { Strength- } \\
\text { MPa }\end{array}$ & $\begin{array}{c}1053.7+78.6 \mathbf{R}+9.8 \mathbf{t}- \\
21.8 \mathbf{T t}\end{array}$ & 0.940 & 15.9 \\
\hline $\begin{array}{c}\text { Ultimate } \\
\text { Strength- } \\
\text { MPa }\end{array}$ & $1375.0+45.6 \mathbf{R}-8.1 \mathbf{T}$ & 0.847 & 14.3 \\
\hline $\begin{array}{c}\text { Reduction in } \\
\text { Area- } \%\end{array}$ & $\begin{array}{c}13.0-2.9 \mathbf{R}-2.4 \mathbf{R T}+2.3 \mathbf{T t} \\
-2.0 \mathbf{R t}\end{array}$ & 0.866 & 1.5 \\
\hline $\begin{array}{c}0.2 \% \text { Creep } \\
\text { Life-h }\end{array}$ & $\begin{array}{r}500.5+172.7 \mathbf{R}-80.5 \mathbf{T}- \\
85.3 \mathbf{t}\end{array}$ & 0.751 & 108.9 \\
\hline $\begin{array}{c}\text { Log(Dwell } \\
\text { Fatigue } \\
\text { Crack }\end{array}$ & $\begin{array}{c}-6.967+0.416 \mathbf{R}-0.343 \mathbf{T}- \\
\text { Growth }\end{array}$ & 0.570 & 0.356 \\
Rate-m/s) & $0.229 \mathbf{t}$ & & \\
\hline
\end{tabular}



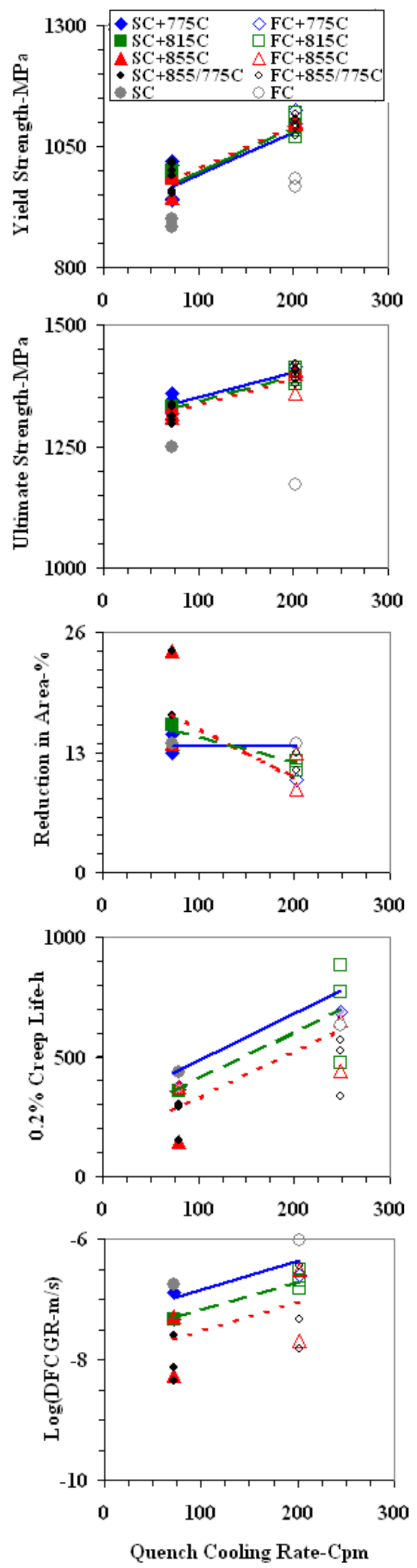

Fig. 6. Heat treatment-mechanical property relationships.
Microstructure-Mechanical Property Relationships

The correspondences between microstructure and mechanical properties for all the different heat treatments are compared in the plots of Fig. 7. Yield strength, ultimate strength, ductility and dwell fatigue crack growth rates are each shown versus the most significant microstructural parameter analyzed in regressions. Creep life was not analyzed in this manner, due to the faster cooling rates of the creep blanks than those for tensile and crack growth specimens with analyzed microstructures. Regression trials were performed to model these properties using standardized variables of both linear and square root transformations of inverse $\gamma_{S}{ }^{\prime}$ diameter $\left(1 / d_{S}\right.$ and $\left.1 / d_{S}{ }^{0.5}\right)$ and inverse $\gamma_{T}{ }^{\prime}$ diameter $\left(1 / d_{T}\right.$ and $\left.1 / \mathrm{d}_{\mathbf{T}}{ }^{0.5}\right)$, in order to assess relationships consistent with precipitation hardening models. $\gamma_{\mathrm{s}}{ }^{\prime}$ and $\gamma_{\mathrm{T}}{ }^{\prime}$ volume fractions were highly cross-correlated, and could not both be included in the stepwise regressions. This is because the total volume fraction of $\gamma_{\mathrm{S}}{ }^{\prime}$ plus $\gamma_{\mathrm{T}}{ }^{\prime}$ was near constant for all heat treatments, consistent with that predicted by the superalloy chemistry and thermodynamics. Therefore, only linear and square root transformations of $\gamma_{\mathrm{s}}{ }^{\prime}$ volume fraction $\left(\mathrm{f}_{\mathrm{S}}\right.$ and $\left.\mathrm{f}_{\mathrm{S}}{ }^{0.5}\right)$ were included in these regression trials. Stepwise regression was then used to assess the significance of each term and their interaction terms: $1 / \mathrm{d}_{\mathrm{S}}, \quad 1 / \mathrm{d}_{\mathrm{T}}, \quad \mathrm{f}_{\mathrm{S}}, \quad\left(1 / \mathrm{d}_{\mathrm{S}}\right)\left(1 / \mathrm{d}_{\mathrm{T}}\right), \mathrm{f}_{\mathrm{S}} / \mathrm{d}_{\mathrm{S}}, \mathrm{f}_{\mathrm{S}} / \mathrm{d}_{\mathrm{T}}$. The square root transformations of each variable were assessed separately, in the same manner. The two-step aging heat treatment mechanical property and microstructural results were included in this analysis. However, data from as-quenched specimens were again not included in these regressions, due to their divergent microstructures and mechanical responses. Each variable was standardized as before.

The resulting regression equations are summarized in Table IV. Square root transformations of these terms gave better regression correlations that the linear terms. Yield strength increased with decreasing $\gamma_{\mathrm{s}}{ }^{\prime}$ size, and was enhanced for combinations of low $\gamma_{\mathrm{s}}{ }^{\prime}$ size and low $\gamma_{\mathrm{T}}{ }^{\prime}$ size, and combinations of low $\gamma_{\mathrm{T}}{ }^{\prime}$ size and high $\gamma_{s}{ }^{\prime}$ volume fraction. Tensile strength also increased with decreasing $\gamma_{s}^{\prime}$ size, and was enhanced at combinations of low $\gamma_{s}{ }^{\prime}$ size and high $\gamma_{s^{\prime}}^{\prime}$ volume fractions. Reduction in area increased with increasing $\gamma_{s}^{\prime}$ size. Dwell fatigue crack growth rate decreased with increasing $\gamma_{T}^{\prime}$ size.

The regressions of yield and ultimate strength with $\gamma_{\mathrm{S}}{ }^{\prime}$ and $\gamma_{\mathrm{T}}{ }^{\prime}$ sizes and $\gamma_{\mathrm{T}}{ }^{\prime}$ volume fraction were quite satisfactory, giving $\mathrm{R}_{\mathrm{adj}}{ }^{2}$ and root mean square error values comparable to those of regressions using the controlled heat treat conditions. The inverse dependence of strength on $\gamma_{s}^{\prime}$ size (Fig. 7) is consistent with the predominance of precipitate shearing by strongly coupled dislocation pairs for all samples given aging heat treatments. The associated models $[7,14]$ would imply strength is proportional to $(\mathrm{f} / \mathrm{d})^{0.5}$ here. However, shearing of relatively small $\gamma_{\mathrm{T}}{ }^{\prime}$ would not require coupled dislocations to travel through the precipitate. Strength in this case was believed to be proportional to $1 / \mathrm{d}^{0.5}$. The regression results indicated both terms significantly affected yield strength here, and included contributions of both $\gamma_{\mathrm{S}}{ }^{\prime}$ and $\gamma_{\mathrm{T}}{ }^{\prime}$. The $\gamma_{\mathbf{T}}{ }^{\prime}$ here is near the critical size of $25 \mathrm{~nm}$ estimated in these references as necessary to require shearing of precipitates by strongly coupled dislocation pairs. However, over the entire range of precipitate sizes present here, it appears that both shearing modes could be operative. Ultimate strength was significantly influenced by size and volume fraction only of the 
$\gamma_{s}^{\prime}$. This is consistent with the smaller changes of ultimate tensile strength for different aging heat treatment conditions. Recall aging heat treatments had greater effects on $\gamma_{\mathbf{T}}{ }^{\prime}$ than on $\gamma_{\mathbf{s}}{ }^{\prime}$.

Table IV. Microstructure-Mechanical Property Regressions.

\begin{tabular}{|c|c|c|c|}
\hline Response & Equation & $\mathrm{R}_{\mathrm{adj}}{ }^{2}$ & $\begin{array}{l}\text { Rms } \\
\text { Error }\end{array}$ \\
\hline $\begin{array}{l}\text { Yield Strength- } \\
\mathrm{MPa}\end{array}$ & $\begin{array}{c}1078.0+79.1\left(\mathbf{1} / \mathbf{d}_{\mathbf{S}}{ }^{0.5}\right)- \\
56.7\left(\mathbf{1} / \mathbf{d}_{\mathbf{S}}{ }^{0.5}\right)\left(\mathbf{1} / \mathbf{d}_{\mathbf{T}}{ }^{0.5}\right)+ \\
\quad 61.0\left(\mathbf{1} / \mathbf{d}_{\mathbf{T}}{ }^{0.5}\right) \mathbf{f}_{\mathbf{S}}{ }^{0.5}\end{array}$ & 0.930 & 16.3 \\
\hline $\begin{array}{c}\text { Ultimate } \\
\text { Strength-MPa }\end{array}$ & $\begin{array}{c}1366.7+47.3\left(\mathbf{1} / \mathbf{d}_{\mathrm{S}}{ }^{0.5}\right)+ \\
24.0\left(\mathbf{1} / \mathbf{d}_{\mathrm{S}}{ }^{0.5}\right) \mathbf{f}_{\mathrm{S}}{ }^{0.5}\end{array}$ & 0.795 & 16.7 \\
\hline $\begin{array}{c}\text { Reduction in } \\
\text { Area-\% }\end{array}$ & $13.5-4.1\left(\mathbf{1} / \mathbf{d}_{\mathrm{s}}^{0.5}\right)$ & 0.358 & 3.6 \\
\hline $\begin{array}{c}\text { Log(Dwell } \\
\text { Fatigue Crack } \\
\text { Growth Rate- } \\
\mathrm{m} / \mathrm{s})\end{array}$ & $-7.1+0.6\left(\mathbf{1} / \mathbf{d}_{\mathbf{T}}{ }^{0.5}\right)$ & 0.330 & 0.5 \\
\hline
\end{tabular}

It is evident that such relationships between the $\gamma^{\prime}$ microstructure and mechanical properties, using terms consistent with precipitation hardening models, can model strength with resolution comparable to that of processing-property models commonly used. The microstructures and mechanical properties were assessed here for only two cooling rates and associated cooling paths, and a limited set of aging temperature and time combinations were studied. Superalloy disks would have locations of varying cooling paths, resultant microstructures, and mechanical properties, based on the solution quench process and exact location within each disk. Actual aging temperature and time combinations would also vary with heat treat processing details and exact material location within each disk. Heat transfer codes are now able to model temperature-time history in superalloy disks with increasing fidelity. Microstructure modeling codes are now emerging which can predict $\gamma^{\prime}$ microstructure for these variable temperature-time paths. Microstructure-mechanical property relationships based on deformation concepts, which are easy to implement yet of sufficient resolution, are desirable to then model disk mechanical properties as continuous functions of location. The present results indicate this may be practical for supersolvus disk microstructures using relatively few microstructural parameters. However, additional combinations of cooling paths and aging heat treatments would need to be tested for more complete evaluation of such an approach. For example, dual slope cooling paths have not been tested in this study, but are quite commonly observed in heat treated disks. Selection of these paths could be guided in part by heat transfer model predictions for disks and disk locations of most interest.

Reduction in area and dwell fatigue crack growth rates could not be modeled well here using the selected $\gamma^{\prime}$ microstructure parameters. Reduction in area could be limited by ductility exhaustion mechanisms influenced by parameters such as critical dislocation densities and degree of slip heterogeneity, rather than just precipitate sizes and volume fractions. Dwell fatigue crack growth rates may be controlled by interactions between plastic flow and time dependent response near the crack tip, rather than only traditional precipitation hardening mechanisms. This aspect is further considered elsewhere in these proceedings [19].
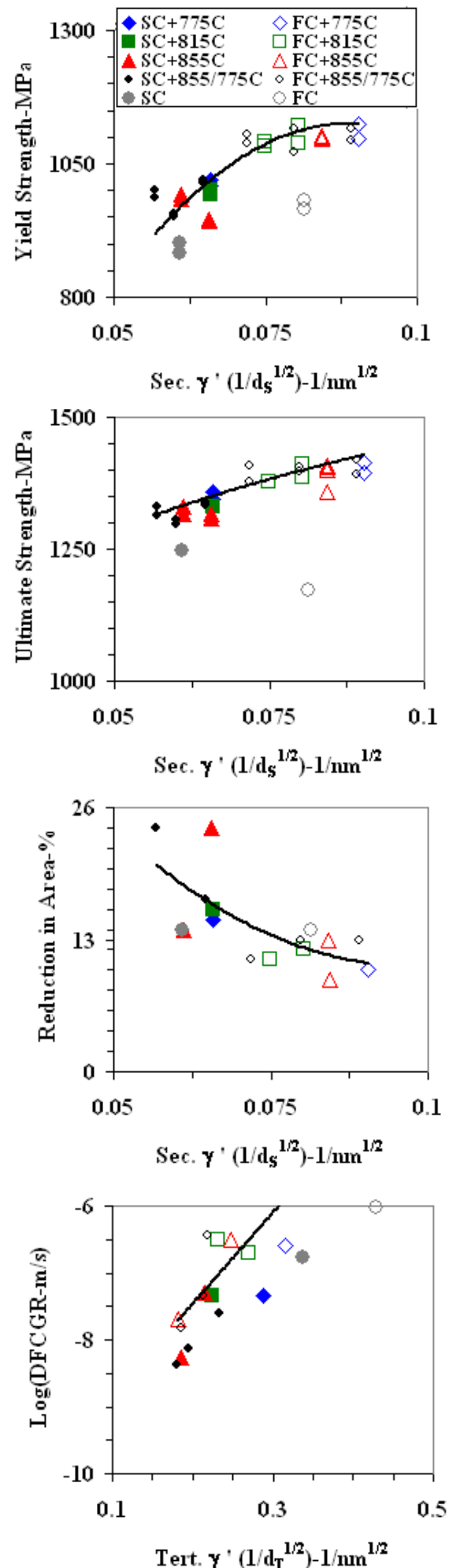

Fig. 7. Microstructure-mechanical property relationships.

Simple bar charts comparing mechanical properties of selected end point heat treatments are shown in Fig. 8. These allow comparison of the trades in mechanical properties available for different cases having one and two-step aging heat treatments. 

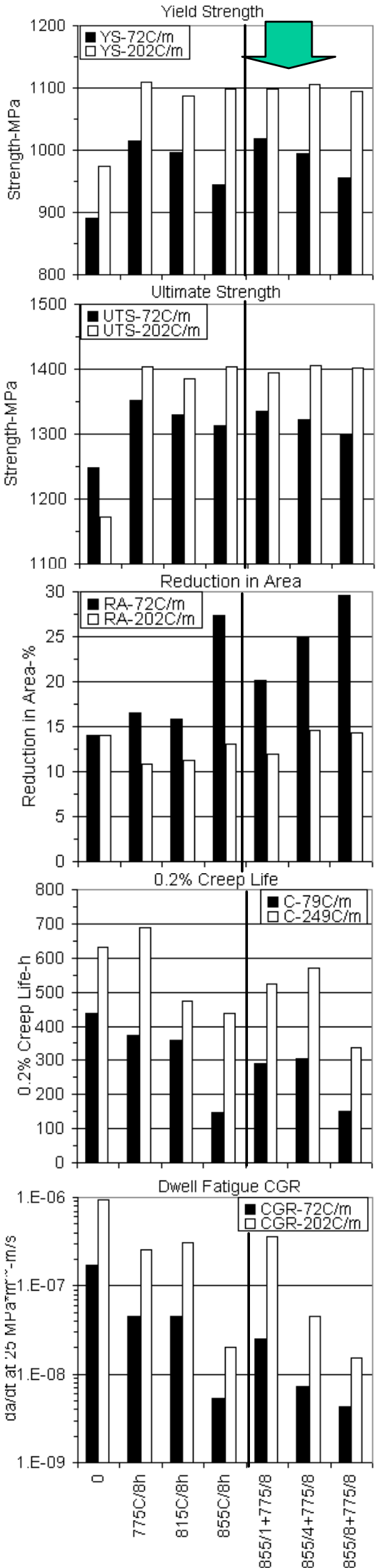

Fig. 8. Trades in mechanical properties for heat treatments.
Close scrutiny of the bar charts in Fig. 8 indicates that the twostep aging heat treatments give somewhat different combinations of all four mechanical properties for each cooling rate, compared to single step aging heat treatments. The balance of properties for aging at $855^{\circ} \mathrm{C}$ for $1-4 \mathrm{~h}$, followed by $775^{\circ} \mathrm{C}$ for $8 \mathrm{~h}$ appears quite favorable, depending on intended application. This is likely associated with subtle alterations in the balance of $\gamma_{\mathrm{S}}{ }^{\prime}$ and $\gamma_{\mathrm{T}}{ }^{\prime}$ sizes and volume fractions compared to that for single step aging heat treatments. The first aging step at $855^{\circ} \mathrm{C}$ increases $\gamma_{\mathrm{s}}{ }^{\prime}$ volume fraction at roughly constant $\gamma_{\mathrm{S}}{ }^{\prime}$ size, while decreasing $\gamma_{\mathrm{T}}{ }^{\prime}$ volume fraction and increasing $\gamma_{T}^{\prime}$ size. The subsequent aging step of $775^{\circ} \mathrm{C} / 8 \mathrm{~h}$ step precipitates additional $\gamma_{\mathbf{T}}^{\prime}$ of finer size. Additional study is necessary to more fully understand how these alterations in microstructure effect mechanical response, and how such effects could be leveraged for further property manipulation.

Additional work is planned in several areas. Creep tests are underway for smaller specimens extracted from the same size blanks as tensile and fatigue crack growth specimens, where the microstructures have been well characterized. Then creepmicrostructure relationships can be assessed as previously discussed. Dual slope cooling path heat treatments combining the two cooling rates examined here will also be considered. TEM evaluations of deformed samples will also be undertaken, to compare deformation mechanisms for different microstructures and loading conditions.

\section{Summary of Results and Conclusions}

In summary, the effects of heat treatment and resulting microstructure variations on high temperature mechanical properties were examined for a powder metallurgy disk superalloy LSHR. Blanks were consistently supersolvus solution heat treated, quenched, and aged. Tensile, creep, and dwell fatigue crack growth tests were then performed at $704^{\circ} \mathrm{C}$. Grain size was comparable for all heat treatments. $\mathrm{M}_{23} \mathrm{C}_{6}$ carbide content appeared comparable for the various aged cases. Grain boundaries were more serrated for slow cooled samples, but did not appear to vary with aging heat treatment.

High cooling rates were combined with aging at low temperatures to produce a high volume fraction of uniform, fine $\gamma_{\mathrm{s}}{ }^{\prime}$ combined with a low volume fraction of uniform, fine $\gamma_{\mathrm{T}}^{\prime}$. This microstructure gave relatively high strength and creep resistance, but relatively low ductility and dwell fatigue crack growth resistance. Conversely, lower cooling rates combined with aging at high temperatures produced a lower volume fraction of coarser $\gamma_{\mathrm{s}}^{\prime}$ with some dendritic growth at cube corners, and a high volume fraction of coarser $\gamma_{\mathrm{T}}^{\prime}$. This microstructure gave lower strength and creep resistance, but better ductility and dwell fatigue crack growth resistance.

Samples of high cooling rate with subsequent high temperature aging experienced rapid reductions in $\gamma_{\mathbf{T}}^{\prime}$ volume fraction, with corresponding increases in $\gamma_{s}^{\prime}$ volume fraction and some joining of nearby $\gamma_{\mathrm{s}}^{\prime}$ precipitates. The application of a subsequent aging step at low temperatures precipitated additional, fine $\gamma_{T}^{\prime}$ for a good combination of mechanical properties.

It can be concluded from this work that: 
1) Microstructure-strength relationships can be generated and calibrated through stepwise regression of relatively few $\gamma^{\prime}$ microstructural size and quantity parameters to give predictions of high resolution, as high as traditional process-strength relationships.

2) Yield strength is influenced by both secondary and tertiary $\gamma^{\prime}$ size and volume fraction; while tensile strength appears to be influenced by only secondary $\gamma^{\prime}$ size and volume fraction in this study.

3) Ductility and dwell fatigue crack growth cannot be modeled as well with these few microstructural parameters, as other factors apparently are influential.

4) Aging of fast cooled material at high temperatures can allow rapid exchange of $\gamma_{\mathrm{T}}{ }^{\prime}$ and $\gamma_{\mathrm{S}}{ }^{\prime}$ volume fractions. When combined with a subsequent lower temperature aging heat treatment step, favorable property balances can be achieved. This process of exchanging $\gamma_{\mathrm{s}}{ }^{\prime}$ and $\gamma_{\mathrm{T}}{ }^{\prime}$ volume fractions, as well as the associated merging of $\gamma_{s}^{\prime}$ precipitates, needs to be further explored.

\section{Acknowledgments}

The authors would like to acknowledge Tony Banik, now of Allvac, and Ian Dempster of Wyman-Gordon PCC for LSHR material processing. The efforts of Terry McCue of ACS at NASA GRC and Pete Kantzos, now of Honeywell Engine Systems, are also greatly appreciated. This work is supported by the NASA Aviation Safety program.

\section{References}

1. J. R. Groh, D. P. Mourer, "Alternate Material for Elevated Temperature Turbine Cooling Plate Applications", Superalloys 2004, ed. K. A. Green, H. Harada, T. E. Howson, T. M. Pollock, R. C. Reed, J. J. Schirra, S. Walston, The Minerals, Metals, \& Materials Society, 2004, pp. 101108.

2. H. Merrick, R. C. Benn, P. R. Bhowal, "High Strength Powder Metallurgy Nickel Base Alloy", U. S. Patent 6,468,368, Washington, D. C. 2002.

3. J. Telesman P. Kantzos, J. Gayda, P. J. Bonacuse, A. Prescenzi, "Microstructural Variables Controlling TimeDependent Crack Growth in a P/M Superalloy". Superalloys 2004, ed. K. A. Green, et al, TMS, 2004, pp. 215-224.

4. J. Gayda, T. P. Gabb, P. T. Kantzos, "The Effect of Dual Microstructure Heat Treatment on an Advanced Nickel-Base Disk Alloy", Superalloys 2004, ed. K. A. Green, et al, TMS, 2004, pp. 323-330.

5. J. R. Groh, "Effect of Cooling Rate From Solution Heat Treatment on Waspaloy Microstructure and Properties", Superalloys 1996, eds. R. D. Kissinger, D. J. Deye, D. L. Anton, A. D. Cetel, M. V. Nathal, T. M. Pollock, D. A. Woodford, The Minerals, Metals, \& Materials Society, Warrendale, PA, 1996, pp. 621-626.

6. J. Schirra, P. L. Reynolds, E. S. Huron, K. R. Bain, D. P. Mourer, "Effect of Microstructure (and Heat Treatment) on the $649^{\circ} \mathrm{C}$ Properties of Advanced P/M Superalloy Disk Materials", Superalloys 2004, ed. K. A. Green, et al, TMS, 2004, pp. 341-350.

7. W. W. Milligan, E. L. Orth, J. J. Schirrra, M. F. Savage, "Effects of Microstructure on the High Temperature Constitutive Behavior of IN100", Superalloys 2004, ed. K. A. Green, et al, TMS, 2004, pp. 331-340.

8. H. Loyer-Danflou, M. Marty, A. Walder, "Formation of Serrated Grain Boundaries and Their Effect on the Mechanical Properties in a P/M Nickel Base Superalloy", Superalloys 1992, eds. S. D. Antolovich, R. W. Stusrud, R. A. MacKay, D. L. Anton, T. Khan, R. D. Kissinger, D. L. Klarstrom, The Minerals, Metals, \& Materials Society, Warrendale, PA, 1992, pp. 63-72.

9. E. S. Huron, K. R. Bain, D. P. Mourer, J. J. Schirra, P. L. Reynolds, E. E. Montero, "The Influence of Grain Boundary Elements on Properties and Microstructures of P/M Nickel Base Superalloys", Superalloys 2004, ed. K. A. Green, et al, TMS, 2004, pp. 73-82.

10. T. P. Gabb, D. G. Backman, D. Y. Wei, D. P. Mourer, D. U. Furrer, A. Garg, D. L. Ellis, " $\gamma$ ' Formation in a Nickel-base Disk Superalloy”, Superalloys 2000, eds. T. M. Pollock, R. D. Kissinger, R. R. Bowman, K. A. Green, M. McLean, S. L. Olson, J. J. Schirra, The Minerals, Metals, \& Materials Society, Warrendale, PA, 2000, pp. 405-414.

11. H.-J. Jou, P. Voorhees, G. B. Olsen, "Computer Simulations for the Prediction of Microstructure/Property Variation in Aeroturbine Disks", Superalloys 2004, ed. K. A. Green, et al, TMS, 2004, pp. 877-886.

12. T. A. Parthasarathy, S. I. Rao, D. M. Dimiduk, "A Fast Spreadsheet Model for the Yield Strength of Superalloys", Superalloys 2004, ed. K. A. Green, et al, TMS, 2004, pp. 887-896.

13. A. J. Ardell, "The Effect of Volume Fraction on Particle Coarsening: Theoretical Considerations", Acta Metallurgica, 1972, V. 20, pp. 61-71.

14. M. P. Jackson, R. C. Reed, "Heat Treatment of Udimet 720Li: The Effect of Microstructure on Properties", Mat. Sci. Eng., V. A259, 1999, pp. 85-97.

15. B. F. Flageolet, P. Villechaise, M. Jouiad, J. Mendez, "Ageing Characterization of the Powder Metallurgy Superalloy N18”, Superalloys 2004, ed. K. A. Green, T. M. Pollock, H. Harada, T. E. Howson, R. C. Reed, J. J. Schirra, S. Walston, TMS, 2004, pp. 371-379.

16. R. J. Mitchell, M. C. Hardy, M. Preuss, S. Tin, "Development of $\gamma^{\prime}$ Morphology in P/M Rotor Disc Alloys During Heat Treatment", Superalloys 2004, ed. K. A. Green, et al, TMS, 2004, pp. 361-370.

17. D. Locq, P. Caron, S. Raujol, F. Pettinari-Sturmel, A. Coujou, N. Clement, "On the Role of Tertiary $\gamma^{\prime}$ Precipitates in the Creep Behaviour at $700^{\circ} \mathrm{C}$ of a PM Disk Superalloy", 
Superalloys 2004, ed. K. A. Green, et al, TMS, 2004, pp. 179-188.

18. T. P. Gabb, A. Garg, D. L. Ellis, K. M. O'Connor, "Detailed Microstructural Characterization of the Disk Alloy ME3", NASA TM-2004-213066, National Aeronautics and Space Administration, Washington, D.C., 2004.

19. J. Telesman, T. P. Gabb, A. Garg, P. Bonacuse, J. Gayda, "Effect of Microstructure on Time Dependent Fatigue Crack Growth Behavior in a P/M Turbine Disk Alloy", Superalloys 2008, ed. K. A. Green, et al, The Mining, Metallurgy \& Materials Society, 2008. 